\title{
Computer-Controlled In Situ Gas Reactions via a MEMS-based Closed-Cell System
}

\author{
L. F. Allard ${ }^{1}$, W. C. Bigelow ${ }^{2}$, Z. Wu ${ }^{1}$, S. H. Overbury ${ }^{1}$, K. A. Unocic ${ }^{1}$, M. Chi ${ }^{1}$, W. B. Carpenter ${ }^{3}$, \\ F. S. Walden ${ }^{3}$, R. L. Thomas ${ }^{3}$, D. S. Gardiner ${ }^{3}$, B. W. Jacobs ${ }^{3}$, D. P. Nackashi ${ }^{3}$ and J. Damiano ${ }^{3}$ \\ 1. Physical Sciences Directorate, Oak Ridge National Laboratory, Oak Ridge, TN, USA. \\ 2. Department of Materials Science \& Engineering, University of Michigan, Ann Arbor, MI, USA. \\ 3. Protochips, Inc., Raleigh, NC, USA.
}

Closed-cell TEM specimen holders based on MEMS-fabricated heater devices allow atomic resolution to be obtained on e.g. catalyst materials, at elevated temperatures and pressures [1-3]. We have shown that resolution in STEM imaging mode is largely unaffected by the gas pressure and cell temperature [4]. Understanding the physical characteristics and behavior of the MEMS heater devices in different gas environments has enabled development of an in situ reaction cell that is easy to use, and generates more reliable data. The holder-based approach does not require a dedicated (S)TEM, and most existing microscopes are compatible with current holder designs.

The Protochips Atmosphere ${ }^{\mathrm{TM}}$ Gas E-cell enables the ultra-stable heating performance of the Aduro ${ }^{\mathrm{TM}}$ thin film heater devices, and incorporates a fully automated, computer-controlled gas delivery manifold with near-instantaneous closed-loop temperature control, independent of the gas pressure and composition. Figure 1 shows the holder tip, and a cross-section schematic showing the narrow gap (nominally $5 \mu \mathrm{m}$ ) between the heater membrane and an amorphous SiN window between which the gas is contained. The cell can be operated in both static and flowing gas conditions; careful selection of the supply and return capillary diameters ensures that the pressure in the reaction cell is essentially the same as the pressure measured in the chosen (of 3) supply tank. Figure 2 shows the gas manifold, and the computer GUI that is used to control the experiment. Several unique features are included, such as an automated Pump/Purge cycle to prepare the cell for the chosen reaction gas, automated shut down of the experiment, and most importantly, a running data record of the temperature and pressure that can be registered precisely to each time-stamped digital image recorded during the experiment. Examples of the operation of the Atmosphere system for studies of gas reactions on fine clusters, nanoparticles, and "bulk" alloy powders will be discussed; two examples are given here. Figure 3 shows the oxidation behavior of 22-atom clusters of $\mathrm{Au}\left(\mathrm{Au}_{22}\right)$ on titania (P25 powder). Figures 3a,b show the starting condition of the clusters at $100^{\circ} \mathrm{C}$ with "vacuum" ( $<1$ Torr) in the cell and then under 300 Torr of $\mathrm{O}_{2}$ with the latter image recorded after only a few minutes at the higher pressure. Some minor cluster consolidation is seen e.g. between inset areas $\mathrm{A}$ and $\mathrm{B}$. Temperature was increased in $50^{\circ} \mathrm{C}$ increments with additional imaging of the same sample areas, with a final set recorded at $400{ }^{\circ} \mathrm{C}$ as shown in Fig. 3c. Further cluster growth/consolidation and possible evaporation is suggested by areas such as insets B and $\mathrm{C}$ shown in Figs. 3d,e. Figure $3 \mathrm{~d}$ was recorded at $10 \mathrm{Mx}$, and even in the gas cell some discrete atoms can be discerned in the clusters. Figure 4 shows oxidation of a NiAl alloy particle prepared by crushing powder of 30-50 $\mu \mathrm{m}$ particle size. Initial imaging (Fig. 4a) at $300^{\circ} \mathrm{C}$ in a full atmosphere of air showed no discernible changes over time. Heating to $800^{\circ} \mathrm{C}$ (Fig. 4b) caused the formation of a "frothy" coating that was shown by pre- and post-reaction EDS analysis (Figs. 4c,d) to be largely AlOx. Further details of both these experiments will be discussed [5].

\section{References}

[1] LF Allard et al., Microsc. Microanal. 18 (2012), p. 656.

[2] JF Creemer et al., Ultramicroscopy 108(9) (2008), p. 993. 
[3] HL Xin, et al., Microsc Microanal 19 (2013), p. 1.

[4] LF Allard, et al., Microsc. Microanal. 20 (Suppl 3) (2014), p. 1572.

[5] Microscopy research at ORNL sponsored in part by the U.S. Dept. of Energy (DOE), Office of Energy

Efficiency and Renewable Energy, Vehicle Technologies Program, as part of the Propulsion Materials Program, and (ZW and SO) by the DOE Office of Science, Basic Energy Sciences, under Award \# ERKCC96.
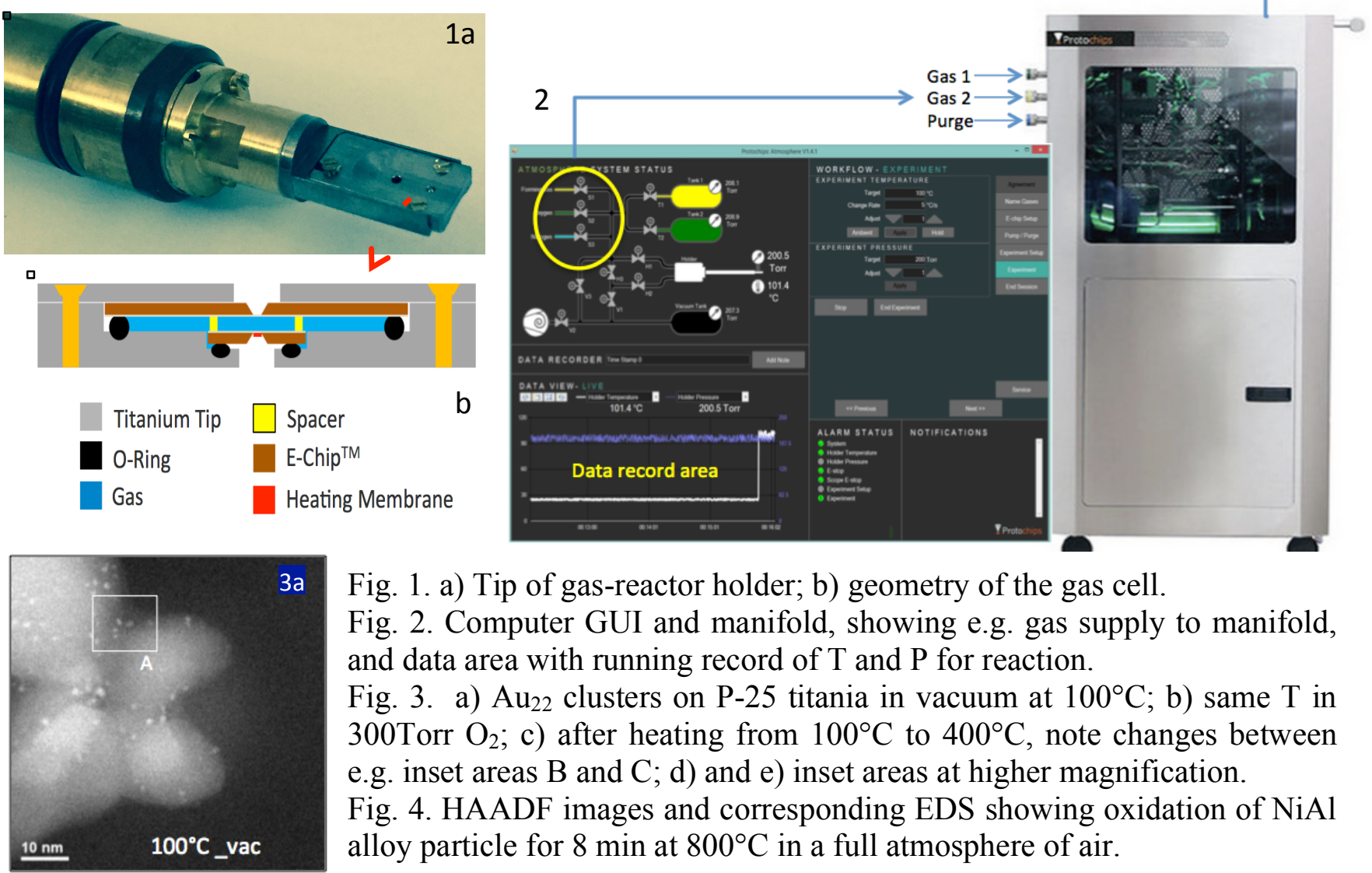

Fig. 1. a) Tip of gas-reactor holder; b) geometry of the gas cell.

Fig. 2. Computer GUI and manifold, showing e.g. gas supply to manifold, and data area with running record of $\mathrm{T}$ and $\mathrm{P}$ for reaction.

Fig. 3. a) $\mathrm{Au}_{22}$ clusters on $\mathrm{P}-25$ titania in vacuum at $100^{\circ} \mathrm{C}$; b) same $\mathrm{T}$ in 300Torr $\mathrm{O}_{2}$; c) after heating from $100^{\circ} \mathrm{C}$ to $400^{\circ} \mathrm{C}$, note changes between e.g. inset areas $\mathrm{B}$ and $\mathrm{C}$; d) and e) inset areas at higher magnification.

Fig. 4. HAADF images and corresponding EDS showing oxidation of $\mathrm{NiAl}$ alloy particle for $8 \mathrm{~min}$ at $800^{\circ} \mathrm{C}$ in a full atmosphere of air.
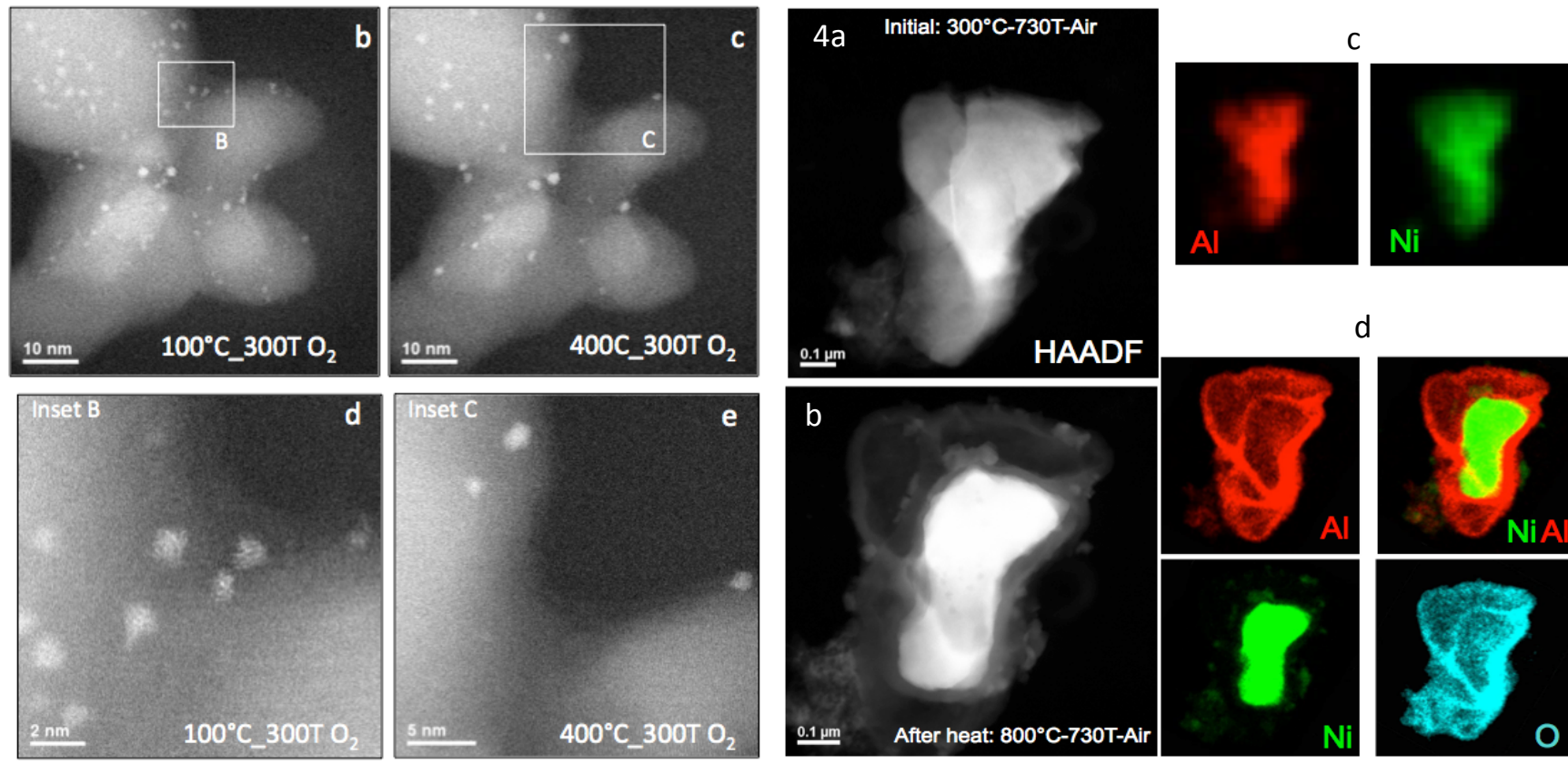

d

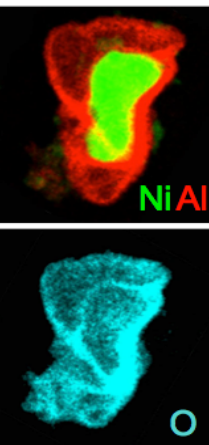

